\title{
Integrating the Humanities into Entertainment and Music Business and Performing Arts Students' Learning Through Artists' Biography and Autobiography
}

\author{
Beverly Schneller \\ Belmont University \\ This paper was presented at the 2018 International Summit of the \\ Music \& Entertainment Industry Educators Association
}

March 22-24, 2018

$\underline{\text { https://doi.org/10.25101/18.13 }}$

\section{Abstract}

This presentation will describe how I created and teach a Humanities elective in the General Education Core at Belmont University in Nashville, Tennessee called "Entertaining Lives: Life Stories of Artists, Celebrities, and Fame." The course enrollment is restricted to students in our undergraduate programs in Audio Engineering Technology, Music Business, Entertainment Industry Studies, Business, and the Performing Arts degrees. The course enables students to study life writing and narrative (humanities) through the stories of noted figures in music, television, sports, dance, and the entertainment industry (King, West, D'Amboise, Jackie Robinson, L. Russell Brown, and others). The first edition of the course was a standalone elective and the second was in a linked cohort with a course in the music industry on film, team-taught with Dr. Clyde Rolston of Belmont University. Through innovative applied projects to augment the readings (storyboards, fantasy artist drafts, and other team projects), I am able to teach students more about the entertainment and music business through a lens that connects with them as Gen Z learners - personal stories of career journies and discernment. In this way, the requirements of the General Education Core are customized to the largest undergraduate majors in our university, and students are able to find relevance in the Liberal Arts curriculum as well as in their desired professional education.

Keywords: biographical writing, applied learning, entertainers, professional course pedagogy, general education, humanities, music industry pedagogy, entertainment industry pedagogy
In the fall semester of 2017, I designed and piloted a Humanities elective in our General Education Program (called the BELL Core) on the theme "Entertaining Lives: Biographies and Autobiographies of Noted Entertainers." Working with the University Registrar and my college, we populated the class mainly with students enrolled in the Mike Curb College of Entertainment and Music Business, who are pursuing a range of undergraduate degrees - the BBA, BA, BS, and BFA. In Curb, students may earn degrees in Music Business, Audio Engineering Technology, Entertainment Industry Studies, Motion Pictures, Publishing, and Media Studies. One of my goals for teaching is to engage students in the General Education program with coursework that meets them at their main areas of interest in creativity and in the arts and entertainment fields - either through the lens of business or as a performer, or both. To that end, "Entertaining Lives" enabled students to examine the lives of a range of celebrities in a broadly defined field of entertainment. Readings were supplemented with assigned YouTube artifacts - music videos, movies, documentaries, and interviews to give a more intimate vision of each subject.

To make the course appropriately focused as the Humanities elective, I concentrated on the genres of biography and autobiography, teaching the students the elements of narrative life writing augmented with critical examinations of the psychologies of fame, celebrity, and reputation as those social constructs of success intersected with the life writing. Understanding authorial intent was essential to the course, as writers' choices determine how we know the biographical and autobiographical subjects.

The fall version of the course featured James Weldon Johnson, Barbara Stanwyck, Jacques D'Amboise, Nancy Dickerson, Jackie Robinson, Carole King, L. Russell Brown, and Kanye West. We had two guest speakers, one from our dance program at Belmont who led a master class 
in her graduate program with D'Amboise, and the other was singer-songwriter, L. Russell Brown, who lives in Nashville. He came to our class and told his story while answering questions about his narrative choices for his memoir, The Quintessential Hitman (2017). We discovered common themes and experiences in all the entertainers' life stories. For example, they all touched on family, education, decisions, expectations, disappointments, successes, and the things that shaped them into the artists that they are. In this way, students saw some of the constants associated with life writing, while learning about how the authors crafted their stories to showcase a "reading" of the biographical subject within a specific context and for a range of purposes.

The course goals were as follows:

- Familiarize you with how autobiography and biography can be written

- Create awareness of how the lives of others are a reflection of ourselves and our culture

- Improve your ability to write narrative

- Improve your ability to integrate multimedia and social media sources into academic projects, thoughtfully and purposefully

- Enhance oral and written communication skills

- Raise sensitivity to diverse people's lives, stories, perspectives, and experiences and how to "see things differently"

With these Learning Outcomes:

- Focused reading of narrative work

- Practice in extracting key points from narrative writing

- Evaluation of first and second person "authenticity" and truth claims

- Identifying and selecting secondary and social media materials for academic communication purposes

- Writing for exams, short prose, and longer narrative

Because the course is reading intensive, I intentionally designed vehicles that gave students more than the standard Socratic experiences with the focus on affirmation of their reading. In our class, we had five applied projects - a poster session on creativity, a Barbara Stanwyck festival planning event, a Fantasy Broadcasters Draft focused on women in media, a Jackie Robinson storyboard, and a Kanye West scavenger hunt. I made each of these activities up from scratch, with the other assessments being tests on the readings, and their Artist Project, a fifteen-page illustrated booklet (modeled on their Stanwyck book) on an entertainment figure of their choice.

Success with the applied projects was measured by students' ability to take the lives in context to solve the "prob- lem" the project presented, extrapolate significances from the details in the texts and videos, and create new knowledge using the life for a specific real world purpose. At the end of each project, we discussed what the students learned and if they had had fun in the process. Answers were in the affirmative and uniformly positive.

A secondary goal of especial import in arts and entertainment careers is successful networking, which these group projects emphasized. With a class of mostly freshmen (18 of 21), students were able to experience each other as team member experts. For instance, the motion pictures students were familiar with storyboard techniques, students from Los Angeles were particularly familiar with the kinds of venues where the Stanwyck festival might make the most money, and none of them really knew anything about television news or women broadcasters, so they all learned together.

For this assignment, I created the scenario that Oprah Winfrey was planning to produce a new show featuring women journalists for her OWN cable network and needed a dream team to create the broadcast. The student group leaders drew names of prominent and active women journalists from a hat, selected their teams in a student-led draft, and then pitched their show concept to "Oprah." Though they started hesitantly, the bidding for the personalities and the pitches showed they were invested. The Jackie Robinson storyboard combined text knowledge with only visual representation of themes in his life, drawn from the hat.

Similarly, the purpose of the Kanye West scavenger hunt was to create a timeline based on the middle chapters of assigned reading in Mark Beaumont's comprehensive study, Kanye West: God and Monster. For this task, students were given these directions:

- Each of you will receive a "clue" that will allow us to piece together aspects of Kanye West's rise to fame. You will need to form into teams and visit with other classmates to find the details you need to create a timeline for his rise to success. Allow yourself enough time to find the clues, then collect the details and organize them into a timeline. What is on your own clue card may be a one-time match to the timeline or may be used by multiple groups for different timeline themes.

- Find the best way to organize the timeline according to how your group sees his rise to fame.

- Put the timeline on the blue paper for reference and we will discuss the outlines.

The students drew unique clues from my hat and then followed the model of a new staff orientation icebreaker, as they had to talk to every student in the class to collect pieces of the materials they needed for the timeline. They then chose a theme for their timeline and built it according to the 
clues, as the project culminated in reporting out to make one comprehensive timeline on the white board covering the four chapters.

The Artist Project (a.k.a. the research paper) was an opportunity for them to research and compose a biography on an entertainment figure of their choice. They were able to demonstrate their understanding of both how to create a life story and how to package it as merchandise for an entertainer's career. The assignment instructions were worded as follows:

- Artist Project - For this project, you will identify an artist, living or dead, about whom you would like to know more. You will design a pamphlet, like the Barbara Stanwyck book, that has a summary of the subject's life, a list of their major works or what they are best known for, images, and appraisals by others and by you. Your target audience is your peers and your purpose is to narrate the subject's life story from the perspective that they have a story worth telling and worth knowing/remembering.

Subjects, predictably, ranged widely from Bruce Springsteen to Elvis to Robin Williams to Alondra de la Parra, a symphony conductor. Notably, students showed passion and personality in this last assignment, as several told me they chose their subject because of a family connection and for the opportunity to learn more about someone they admired or perceived as a role model.

In the spring semester of 2018, I paired the course with "The Music Business on Film" taught by my colleague, Dr. Clyde Rolston, who is also on the Belmont faculty and in the Curb College. For this version of the course, I taught lives of entertainers who were in the documentaries the students analyzed in the film class. We read Nadine Cohodas' history of the Chess Brothers, Spinning Blues into Gold, and the lives of Darlene Love, Gregg Allman, and Aretha Franklin. We also read Mike Curb's autobiography, Living the Business, and he visited our class. Because the course was offered as a linked learning community within the BELL Core, we were able, thanks to a MEIEA grant and support from the Office of the Provost at Belmont, to take the students on the required co-curricular activities which for us included trips to the Johnny Cash Museum and the Musicians Hall of Fame, both in downtown Nashville, and a day trip to Muscle Shoals to visit the Muscle Shoals Studio, FAME Studio, and a state park located on the Tennessee River, where we heard a presentation by the senior park ranger on folk music associated with the river.

Generation $\mathrm{Z}$ students want to know they have learned immediately; they want connections between classroom and career; and, they seek to be respected and valued for their expertise. The applied projects in this Humanities class served as a window for the students to showcase creativity, required a level of expertise as the playing field was not level, and enhanced their abilities to interact with one another to problem-solve. Through their reading and their projects, students had the chance to see themselves through the comparative lens of others stories of success and failure. As such, the students enriched their own career knowledge while finding themselves entertained by other forms of entertainment - prose narratives, applied and independent projects, interviews, and YouTube materials that gave multiple readings and multiple lives to each of the subjects they studied.

Beverly Schneller was a Professor of English at Belmont University when she presented this paper. Dr. Schneller is now Vice Provost of Academic Affairs at Kentucky State University. She writes: I've had a great career in the academy as a faculty member, an administrator, and a scholar. In addition to my work in the classroom, I am a Teagle Assessment Scholar through the Center of Inquiry at Wabash College. My most recent publications include essays on the history of the music business program at Belmont University, an eighteenth-century author-publisher entrepreneurship case study, and a critical appraisal of the popular fiction of Amish Tripathi.

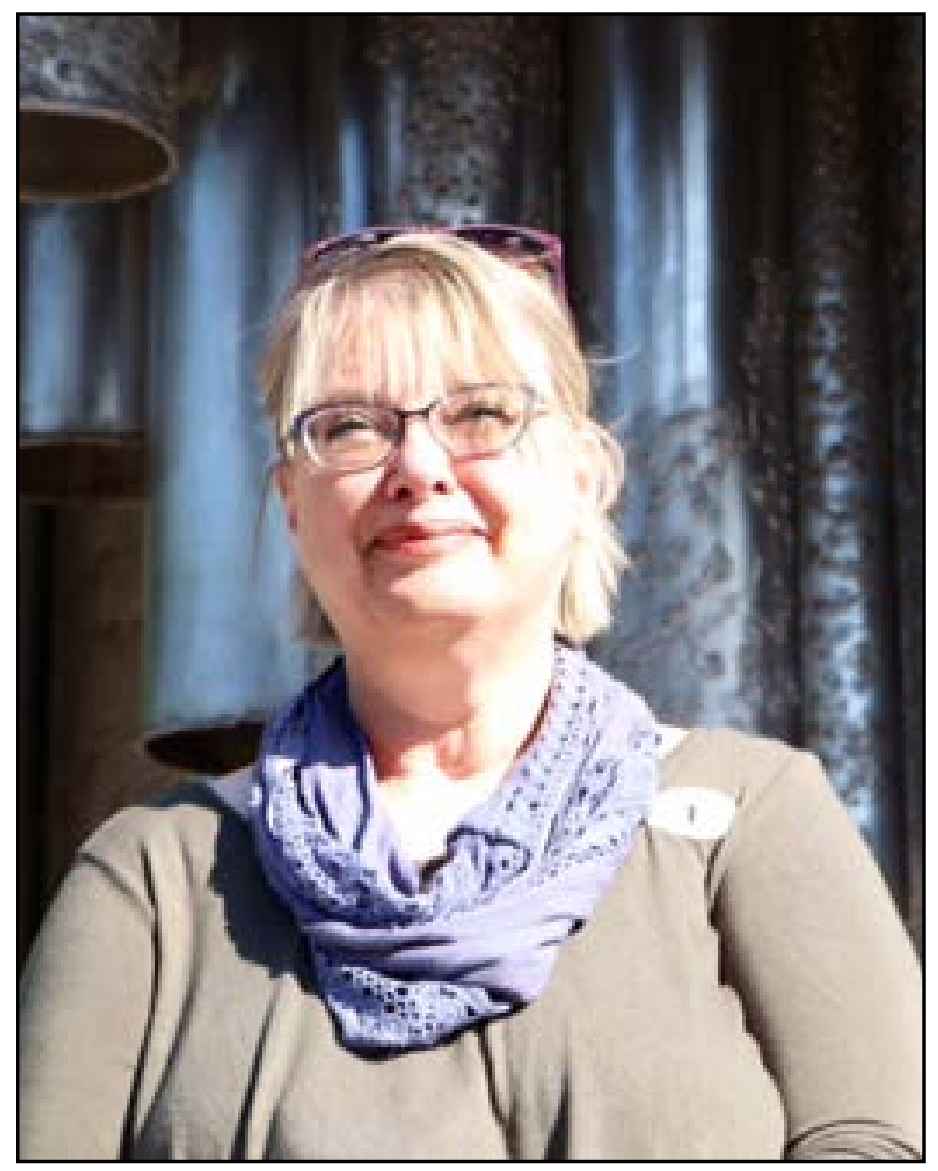




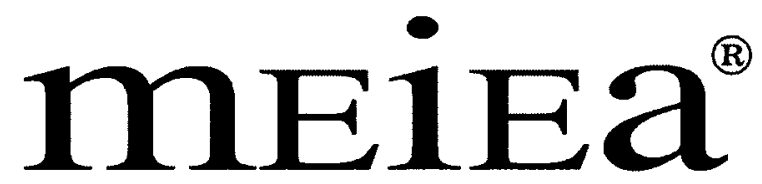

MUSIC \& ENTERTAINMENT INDUSTRY

EDUCATORS ASSOCIATION

\section{PROCEEDINGS OF THE \\ 2018 INTERNATIONAL SUMMIT}

OF THE

\section{MUSIC \& ENTERTAINMENT INDUSTRY EDUCATORS \\ ASSOCIATION}
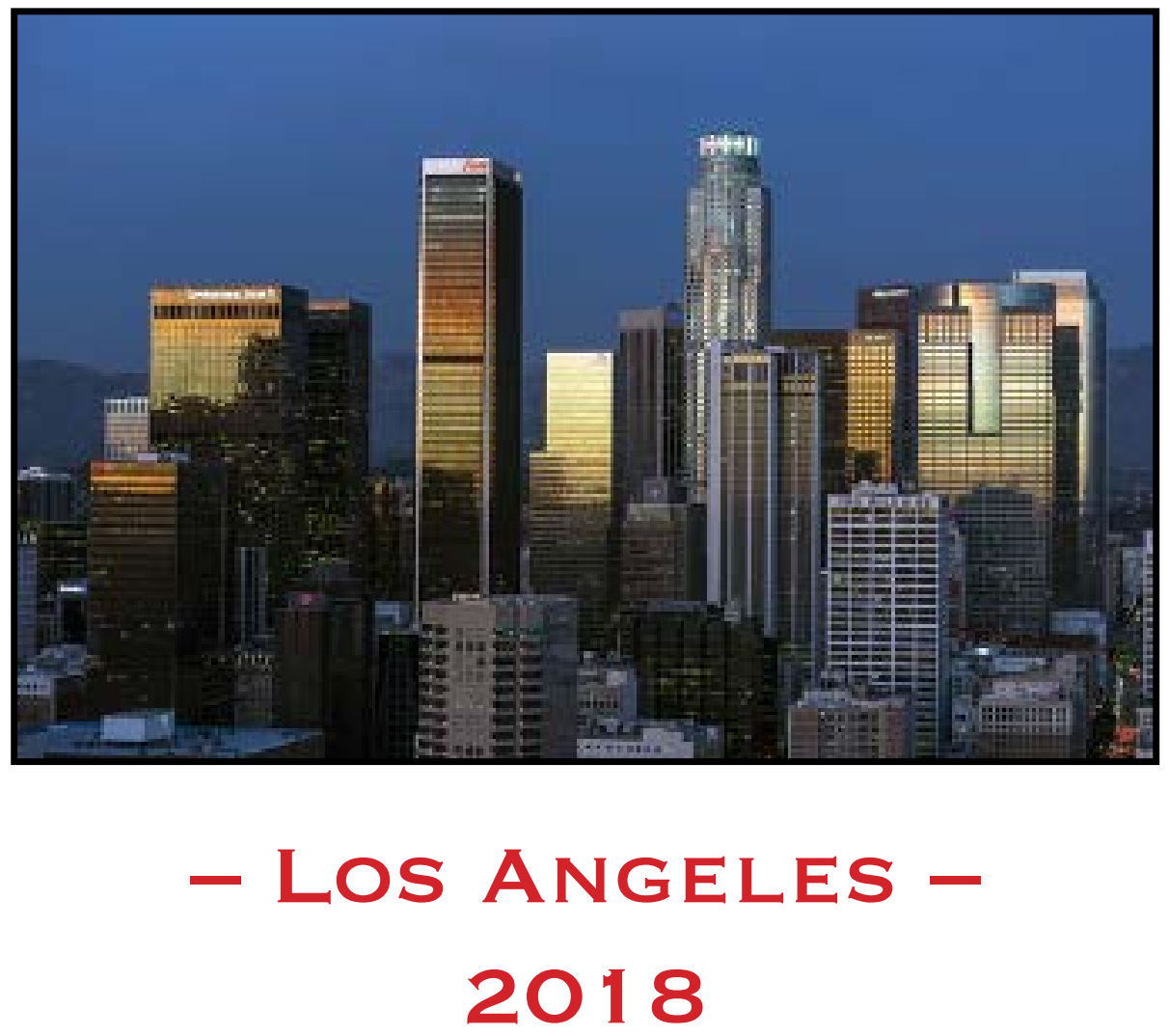

March 22 - 24, $2018 \cdot$ Embassy Suites by Hilton - Los Angeles/Glendale 